\title{
Physiologic Skin Changes During Pregnancy.
}

Aparna Shah ${ }^{1}$, Sushil Jung Shah ${ }^{1}$, Sagar Mani Jha ${ }^{1}$, Nabin Bhakta Shakya ${ }^{1}$, Anil Dangol ${ }^{1}$, Sunil Shakya ${ }^{1}$. ${ }^{1}$ Department of Dermatovenereology, Shree Birendra Army Hospital

\begin{abstract}
Introduction: Approximately $90 \%$ pregnant women are associated with skin changes. The skin undergoes profound alterations during pregnancy as a result of endocrine, metabolic and immunologic changes. Some of these are trivial and chiefly cosmetic, producing no or minor symptoms, others can be distressing and/or of major medical importance. For the necessity of proper and complex care of the pregnant woman,the knowledge about the changes are crucial. The ability of precise diagnosis of physiological skin changes allows specifying the suspected cases of pathologic etiology and referring them to the dermatological referral centers for in-depth diagnosis and eventual treatment. The aim of this study was to identify the incidence and types of dermatological changes in our population.
\end{abstract}

Methods: Pregnant patients attending the antenatal clinic of the Gynecology department in Shree Birendra Hospital, and presenting to the outpatient clinic of the Department of Dermatology, Bir Hospital, for any dermatologic problem, were enrolled. The study spanned a period of 10months (January 2008 to October 2008). We evaluated 150 pregnant women to determine the pattern of pregnancy-induced physiologic skin changes in Nepalese community.

Results: Majority of patient developed dermatological changes in second and third trimester. The commonest sign was hyper pigmentation of the skin followed by striae and edema. Fungal infections were the commonest infections observed,Tineacorporis accounting for 10 (6.66\%) and tineaversicolarwas seen in Eight (5.33\%) patients. Three (2\%) patients hadScabies. A total of 3 patients had sexually transmitted disease. 2 (1.3\%) had Condyloma acuminate and 1 (.006\%) had syphilis.

Conclusions: Hyperpigmentation was the commonest sign (87.33\%) followed by striae (82\%), edema (45.3\%), vascular changes (17.3\%) and melasma (8\%). Varicosities of veins, spider nevi and palmar erythema are relatively less frequent in our population.

Keywords: pregnancy, physiological changes, pigmentation

\section{INTRODUCTION}

Physiological and anatomical alterations develop in many organ systems during the course of pregnancy and delivery. Early changes are due, in part, to the metabolic demands brought on by the fetus, placenta and uterus and, in part, to the increasing levels of pregnancy hormones, particularly those of progesterone and oestrogen. Later changes, starting in mid-pregnancy, are anatomical in nature and are caused by mechanical pressure from the expanding uterus ${ }^{1}$.

The dramatic endocrine, metabolic, vascular and immunologic changes occurring during pregnancy are

\section{Correspondence:}

Maj. Dr. Aparna Shah

Department of Dermatovenereology, Shree Birendra Army Hospital Kathmandu, Nepal

Email:dr10np@yahoo.com

Phone: +977-9841710538 
associated with many alterations in the skin. These changes that occur in a large proportion of pregnant women are regarded as "physiologic skin changes." Increased pigmentation and straie formation are very common during pregnancy, occurring in up to $90 \%$ of women. ${ }^{1}$ Vascular changes include distension, instability, and proliferation of vessels. These vascular alterations result in spider angiomas, palmar erythema, varicosities, cutis marmorata, and gingival edema and redness ${ }^{2}$. Some women notice hair and nail changes ${ }^{2}$. Similarly, the activity of eccrine and sebaceous glands increases, while that of apocrine glands decreases ${ }^{2}$.

Pregnancy induced changes are of various kinds and most of the patients are unaware and concerned about the changes. There are many literatures describing various skin changes during pregnancy. Most of these articles enrolled patients with different skin characteristics than our population.

A Nepalese study was needed to find out various skin manifestations so that a thorough counseling to a pregnant lady could be possible. This study was conducted to determine pregnancyinduced changes in Nepalese women as the skin complexity of our pregnant women are different and we presumed that the skin manifestations will also be different.

\section{METHODS}

Over a period of 10 months (January 2008 to October), 168 pregnant women attending the antenatal clinic and outpatient clinic of the Department of Dermatology, were enrolled in this study. after taking informed written consent, a complete medical and obstetric history of was obtained. Detailed cutaneous and systemic examination was performed. Hemoglobin levels, total and differential leukocyte counts, erythrocyte sedimentation rate, urine examination for sugar and proteins, and microscopy were performed in each case. Each patient was followed up at monthly intervals until delivery. At follow-up visits, each patient was examined clinically; new systemic and cutaneous findings were recorded.Data analysis was done using SPSS 13 software.

\section{RESULTS}

Of the 168 patients, 18 were lost to follow up. So, 150 pregnant women were evaluated. Their age range was 17 to 40 years, with a mean age of 23 years. In contrast to $4(2.66 \%)$ patients who presented in first trimester, majority 146 (97.33\%) presented in the second and third trimesters of pregnancy. 53 (35.33\%) were primigravida and 97 (64.67\%) second gravida. Majority had type III and IV skin. Most of the patients belonged to the lowermiddle and lower socioeconomic classes.
Pigmentary changes were observed in 131 (87.33\%) patients. Of these, increased pigmentation was most common in the areolar region and genitalia, observed in 131 (87.3\%) cases, lineaalba in 125 (83.33\%), melasma in 102 (68\%) (see table 2). Two (1.3\%), patients experienced darkening of their freckles during pregnancy. It regressed spontaneously after delivery, and a history of similar pigmentation during previous pregnancies was found in $11(7.33 \%)$ patients.

Sixty-eight (45.3\%) patients had edema. Of these, 45 (66.17\%) had edema of the feet, while 13 (19.1\%) had edema of the hands and $10(14.7 \%)$ presented with edema of the face. The onset in most cases was in the eighth or ninth month of gestation.

A diffuse mottling type of palmar erythema was noted in $22(14.6 \%)$ cases. Varicose veins, involving the great saphenous system, were seen in $1(0.6 \%)$ cases. One patient had recurrent varicose veins involving the right leg for the last two successive pregnancies. Spider naevi on the chest was seen only in $2(1.33 \%)$ cases.

123(82\%) patients developed striae distensae; 62 had striae due to previous pregnancies. Pruritus associated with striae was present in 30 cases.

Fungal infections were the commonest infections observed, Tineacorporis accounting 10 (6.66\%) and tineaversicolarwas seen in $8(5.33 \%)$ patients. $3(2 \%)$ patients had Scabies.

A total of 3 patients had sexually transmitted disease. $2(1.3 \%)$ had Condyloma acuminate and $1(.006 \%)$ had syphilis.

Pregnancy-induced acne were seen in 6 (4\%) cases. 7 (4.66\%) patients presented with miliria. Hair changes were seen in $18(12 \%)$ cases like dry lusterless hair 11 (7.33\%), sparse scalp hair 9(6\%) and diffuse hair loss 2 (1.33\%). 22 (14.6\%) of pregnant developed nail changes likelongitudinal ridging 11 (7.33\%), leukonychia 2 (1.33\%), brittleness $5(3.33 \%)$, plathonychia 2 (1.33\%) koilonychias $1(0.66 \%)$ and pitting of the nails1 $(0.66 \%)$ were seen.

Table 1. Cutaneous manifestations in study population

\begin{tabular}{|l|c|c|}
\hline $\begin{array}{l}\text { Cutaneous changes in } \\
\text { Pregnant women }\end{array}$ & Number & $\%$ \\
\hline Pigmentation & 131 & $87.33 \%$ \\
\hline Striae distensae & 123 & $82 \%$ \\
\hline Edema & 68 & $15.3 \%$ \\
\hline Palmar erythema & 22 & $14.6 \%$ \\
\hline Varicose vein & 1 & $0.66 \%$ \\
\hline
\end{tabular}




\begin{tabular}{|l|c|c|}
\hline Spider naevi & 2 & $1.33 \%$ \\
\hline Dermatophytes infection & 22 & $14.66 \%$ \\
\hline Scabies & 3 & $2 \%$ \\
\hline Condylomaaccuminata & 2 & $1.3 \%$ \\
\hline Syphilis & 1 & $.006 \%$ \\
\hline Pregnancy induced Acne & 6 & $4 \%$ \\
\hline Miliria & 7 & $4.66 \%$ \\
\hline
\end{tabular}

Table 2.Pigmentory abnormalities in study population

\begin{tabular}{|l|c|c|}
\hline $\begin{array}{c}\text { Pigmentory } \\
\text { abnormalities }\end{array}$ & Number & $\%$ \\
\hline $\begin{array}{l}\text { Pigmentation of Areola } \\
\text { and genitalia }\end{array}$ & 131 & $87.3 \%$ \\
\hline Linea Alba & 125 & $83.33 \%$ \\
\hline Melasma & 102 & $68 \%$ \\
\hline Freckles & 2 & $1.3 \%$ \\
\hline
\end{tabular}

Table 3. Hair Abnormalities in study population

\begin{tabular}{|l|c|c|}
\hline Hair abnormalities & Number & $\%$ \\
\hline Dry lusterless scalp hair & 11 & $7.33 \%$ \\
\hline Sparse scalp hair & 9 & $6 \%$ \\
\hline Diffuse hair loss & 2 & $1.33 \%$ \\
\hline Total & 18 & $12 \%$ \\
\hline
\end{tabular}

Table 4.Nail Changes in study population

\begin{tabular}{|l|c|c|}
\hline $\begin{array}{c}\text { Nail changes in Pregnant } \\
\text { women }\end{array}$ & Number & $\%$ \\
\hline Longitudinal ridging & 11 & $7.33 \%$ \\
\hline Brittle nails & 5 & $3.33 \%$ \\
\hline leuconychia & 2 & $1.33 \%$ \\
\hline Plathonychia & 2 & $1.33 \%$ \\
\hline koilonychia & 1 & $0.66 \%$ \\
\hline Pitting & 1 & $0.66 \%$ \\
\hline Total & 22 & $14.66 \%$ \\
\hline
\end{tabular}

\section{DISCUSSION}

Hyperpigmentation is one of the most common cutaneous changes that occur during pregnancy. In this study, $87.3 \%$ of patients had pregnancy induced hyperpigmentation. In a study of Estève $E$ et $\mathrm{al}^{2}$ and FarhanaMuzaffar et $\mathrm{al}^{3}$, pigmentary changes was the most frequent finding. Mild to moderate, localized, and generalized hyperpigmentation, with accentuation of normally hyperpigmented regions, such as the areolae of the breasts, axillae, and genitalia, was common. Pigmentation of lineaalba and scars was also observed. These findings are consistent with previous reports ${ }^{4}$. The

factors responsible for this preferential darkening may be the greater sensitivity of melanocytes to hormonal stimulation plus the type III or IV skin color in our community.

Melasma was observed in 102 (68\%) patients similar to other study reporting to occur in $50-75 \%$ of pregnant women $^{5,6}$. The onset in most of our cases was during the second and third trimester similar to Martin and Leal-Khouri ${ }^{2}$ report. The cheeks $73(71.5 \%)$ was the most common site of involvement, followed by the nose 61 (59.8\%), upper lips 33 (32.3\%), forehead 21 (20.5\%), chin 12 (11.7\%), and eyebrows 5 (4.9\%). This pattern of distribution is a consistent feature of melasma of pregnancy ${ }^{6,7}$.

An apparently related phenomenon is the darkening and enlargement of nevi ${ }^{7,8}$. The patients noted an increase in the number and size of nevi and two patients experienced darkening of their freckles during pregnancy.

In our study Spider naevi was present only in 2 (1.33\%) patients, which was lesser than the published incidence ${ }^{9}$. The lower incidence in our patient is probably due to the difficulty in visualization because of the dark complexion. Similarly, palmar erythema was noted in a smaller number of patients compared with the number reported in the literature ${ }^{10}$.

Sixty-eight (45.3\%) patients developed pedal edema, which is consistent with other reports ${ }^{6,7}$. In this study, varicosity were noted in only $1(0.6 \%)$ of cases unlike other reports ${ }^{2,3}$. The lower incidence of varicosities in our community may be related to different customs and habits. In the Western world, legs remain in a dependent position more often than in our community where women (mostly housewives) work in a sitting position.

One hundred and twenty three (82\%) patients developed striae distensae similar to study of FarhanaMuzaffaret al $^{6}$ where striae was present in $77.1 \%$ of their case.

A total number of 3 patients were suffering from sexually transmitted disease. 2 (1.3\%) had Condyloma acuminate and $1(.006 \%)$ had syphilis. Syphilis can seriously complicate pregnancy and result in spontaneous abortion, stillbirth, non-immune hydrops, intrauterine growth restriction, and perinatal death, as well as serious sequelae in liveborn infected children. While appropriate treatment of pregnant women often prevents such complications, the major deterrent has been inability to identify the infected women and get them to undergo treatment ${ }^{11}$.

\section{CONCLUSIONS}

Hyperpigmentation was the commonest sign (87.33\%) followed by striae ( $82 \%)$, edema $(45.3 \%)$, vascular changes 
(17.3\%) and melasma (8\%). Varicosities of veins, spider nevi and palmar erythema are relatively less frequent in our population.

\section{REFERENCES}

1. Christopher FC, Gertie FM. Physiological Changes Associated with Pregnancy.Physiology. 1998;9:1.

2. Martin AG, Leal-Khouri S. Physiologic skin changes associated with pregnancy. Int J Dermatol. 1992;31:375-8.

3. Wong RC, Ellis CN. Physiologic skin changes in pregnancy. J Am AcadDermatol. 1989;8:7-11.

4. Fryer JM,Werth VP. Pregnancy associated hyperpigmentation:longitudinal melanonychia. J Am AcadDermatol. 1992;26:493-4.

5. Estève E, Saudeau L, Pierre F, Barruet K, Vaillant L, Lorette G. Physiological cutaneous signs in normal pregnancy: a study of 60 pregnant women.Ann DermatolVenerol.1994;121 (3):22731.

6. Muzaffar F, Hussain I, HaroonTS. Physiologic skin changes during pregnancy: a study of 140 cases. Int J Dermatol. 1998;37 (6):429-31.

7. Murray JC. Pregnancy and the skin. DermatolClin. 1990;8:327-34.
8. Winton GB, Lewis CW. Dermatoses of pregnancy. J Am AcadDermatol. 1982;6:977-98.

9. Black MM, Wilkinson JD. Skin diseases in pregnancy. InKaminetzky, Principles and Practice of Obstetrics and Perinatology. Philadelphia, John Wiley:1987;pp1361-79.

10. Foucar E, Bentley TJ, Laube DW et al. A histopathologic evaluation of nevocellular nevi in pregnancy.Arch Dermatol. 1985;121:350-4.

11. Ellis DL, Wheeland RG. Increased nevus estrogen and progesterone ligand binding related to oral contraceptives and pregnancy. J Am AcadDermatol. 1986;14:25-31.

12. Li CP, Lee FY, Hwang SJ, Chang FY, Lin HC, Lu RH et al. Role of substance $P$ in the pathogenesis of spider angiomas in patients with nonalcoholic liver cirrhosis. Am J Gastroenterol. 1999; 94:502-7.

13. Graham BR,Ebling FJ. The ages of man and their dermatoses. In: Champion, RH, Burton, JL \&Ebling, Fjg. eds. Rook/Wilkinson/Ebling Textbook of Dermatology. Oxford: Blackwell Scientific Publications 1992:7:pp2877-905.

14. Mehmet G, William JL. Syphilis in pregnancy. Sexually Transmitted Infection.2000;76:73-79. 